\title{
Transmission Transition: modernizing U.S. transmission planning to support decarbonization
}

\author{
Alisha Kasam-Griffith ${ }^{1 *}$, Natasha S. Turkmani ${ }^{2}$, Martin J. Wolf ${ }^{3}$, Nina C. Peluso ${ }^{4}$, and Tomas W. Green ${ }^{5}$ \\ Edited by Ruaridh Macdonald and Anthony Tabet
}

\section{HIGHLIGHTS}

- The aging U.S. electrical grid requires major expansion and upgrades to ensure energy access and support decarbonization trends

- Collaboration across regions and types of stakeholders can increase the likelihood of successful modernization of the U.S. energy grid

- Federal policy changes may increase adoption of non-transmission alternatives, which can defer or replace the need for new transmission infrastructure

Decarbonization and degrading infrastructure present twin challenges to the aging U.S. electrical grid, which is vital to the economy, national security, and public well-being. This article addresses challenges around transmission planning processes and policy options to improve these. Specifically, long-term regional transmission planning is hindered by conflicts over the equitable distribution of costs incurred and the benefits achieved by new development, as well as siting and permitting challenges. Policy changes that require comprehensive estimation of benefits and joint trans-regional evaluation can promote projects that fulfill grid requirements effectively and economically. In addition, increased regulatory direction and consideration for non-transmission alternatives (NTAs) and related distribution technologies could defer or replace the need for new transmission.

$\mathbf{T}$ he U.S. Energy Transition is already underway, with considerable progress in decarbonizing the electricity sector. Long-term success hinges on the ability of the transmission system to accommodate changes in how

\footnotetext{
${ }^{1}$ Department of Engineering, University of Cambridge, Cambridge, UK

${ }^{2}$ Charles River Associates, Washington, DC

${ }^{3}$ Yale Center for Environmental Law and Policy, Yale Law School and Yale School of the Environment, New Haven, CT

${ }^{4}$ Institute for Data, Systems, and Society, Massachusetts Institute of Technology, Cambridge, MA

${ }^{5}$ Center for Energy and Environmental Policy Research, Massachusetts Institute of Technology, Cambridge, MA

*Email: aakasam@gmail.com

The authors declare no conflict of interest.

(C) 2020 The Author(s)
}

electricity is generated and consumed. With remote renewable generation added to the grid, long-distance transmission infrastructure will be required to transport this clean energy to distribution centers. Difficulties in forecasting variable renewable generation, coupled with the shrinking output from stable fossil fuel generators, will also require modern transmission technology to ensure that supply and demand remain instantaneously balanced. Electrification of heating, transportation, and industrial processes support the shift to a low-carbon economy, but often require that transmission and distribution lines support peak loads beyond their nominal capacity.

In addition to supporting the nation's decarbonization goals, transmission lines present their own security challenges, as the majority of lines are operating decades beyond their original life expectancy; threats include blackouts, wildfire risk, and vulnerability of the grid to cyberattack [1]. Major investments and upgrades are therefore needed to update the nation's transmission infrastructure, which is critical to preserving national security, economic and technological competitiveness, and energy affordability [2]. This article briefly summarizes the landscape for electric sector organization before addressing the regulatory and socio-economic challenges in transmission planning.

\section{Regulation of the Electrical Grid}

The electrical grid is primarily organized in a top-down manner to transport electricity from generators to users. Transmission lines convey high-voltage electricity from numerous generators, such as power plants and solar farms, to substations. Substations transform electricity to a safer, lower voltage and transfer it to the distribution network for delivery to local customers, who include factories, hospitals, and homeowners. In the continental U.S., the grid consists of multi-state transmission networks, which require planning at the regional level to determine necessary upgrades. Approximately $60 \%$ of electrical supply is administered by regional transmission organizations (RTOs), which control the electrical grid and coordinate the expansion of transmission infrastructure, such as cross-border interconnections that deliver hydropower from Canada to homes in Maryland. The remaining $40 \%$ is managed by regulated utilities, which are typically responsible for the upkeep of local distribution and transmission lines [3] 


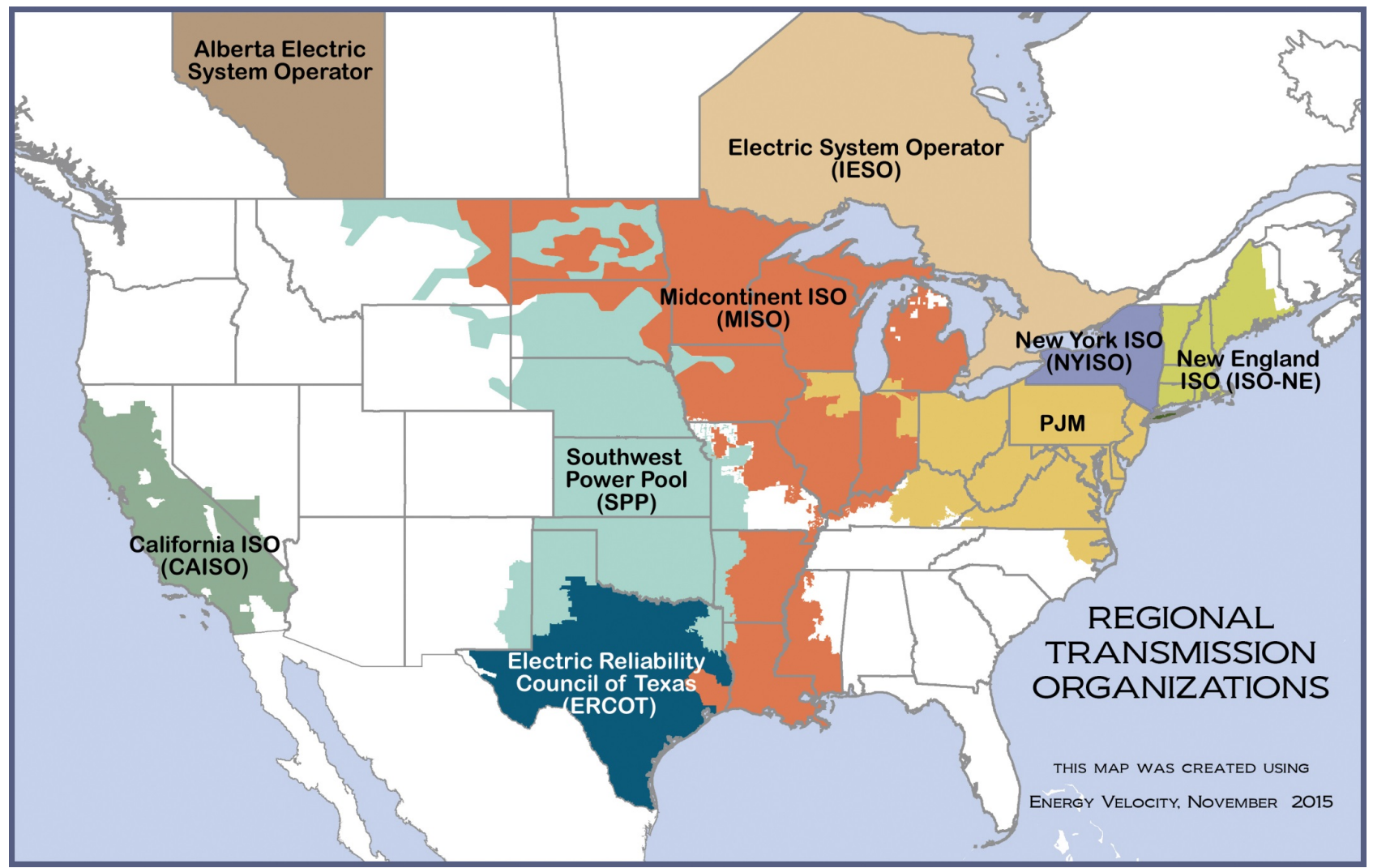

Figure 1: Operating regions of Regional Transmission Organizations and Independent System Operators in North America[6].

The Federal Energy Regulatory Commission (FERC), the central body overseeing interstate electricity planning and wholesale electricity rates, issued FERC Order No. 2000 encouraging the voluntary formation of RTOs to encourage competitive energy trading through open access to transmission [4]. RTOs are independent, non-profit organizations composed of numerous types of members, including integrated utilities, independent energy generators, transmission companies, and energy traders. RTOs coordinate among each other through interregional transmission links, which enhance grid reliability. For example, during the Polar Vortex of 2014, electricity imports from surrounding regions allowed the PJM RTO to keep the lights on [5].

A central piece of FERC's mandate, FERC Order No. 1000 provides the framework for large-scale regional transmission planning and regional cost recovery for the construction of new transmission infrastructure [7]. While FERC approves the processes by which RTOs evaluate plans and allocate costs for transmission infrastructure, states ultimately retain the authority to approve siting and permitting, providing effective veto power to regional infrastructure proposals. The following sections explore the challenges and potential solutions to effective transmission planning, cost allocation, and siting. In addition, non-transmission alternatives and policy options to support their wider implementation are reviewed.

\section{Policy Issues}

Cost Allocation and Benefits Methodologies: New transmission infrastructure would provide great and wide-ranging benefits, yet, cost allocation to beneficiaries remains a critical obstacle to large regional transmission upgrades. Logically, a "beneficiary pays" principle would be implemented, but in the current framework, project developers are effectively recognized as the sole beneficiaries because their projects are what "cause" the need for new transmission. The American Wind Energy Association argues that too much responsibility for network transmission construction falls on the generators, and as a result, proposed generation gets delayed or cancelled due to high costs [8]. In reality, diffuse benefits, such as increased reliability of a region's power supply and less curtailment of renewable energy, are shared by numerous parties.

An alternative cost allocation approach would be to examine the full benefits of proposed interconnection to both electricity consumers and generators, and share the costs accordingly. For example, the Electric Reliability Council of Texas (ERCOT) RTO approved up to $\$ 500$ million to connect wind generators in South and West Texas to load centers primarily in Central and East Texas. Rather than forcing the wind generators to pay for transmission, the total annual cost of all transmission services is spread across Texas and passed onto customers as a dollar-per-kilowatt fee [9].

While ERCOT passed on the infrastructure costs to all consumers, having recognized shared benefits across its 
entire footprint, the value of new transmission infrastructure is often ambiguous and may not be shared equally among all RTO participants. In his testimony before FERC, Judge Posner for the U.S. Court of Appeals wrote the following, in upholding the unanimous decision for the MISO RTO to impose a market-wide tariff to support new transmission:

No one can know how fast wind power will grow. But the best guess is that it will grow fast and confer substantial benefits on the region served by MISO.... There is no reason to think these benefits will be denied to particular subregions of MISO. Other benefits of [multi-value projects], such as increasing the reliability of the grid, also can't be calculated in advance, especially on a subregional basis, yet are real and will benefit utilities and consumers in all of MISO's subregions[10].

FERC Order 1000 describes a framework for transmission planning and cost allocation, and FERC has approved cost allocation processes across the country. However, the question of "who benefits and by how much" is more likely an issue of identifying and quantifying the full benefits of a particular transmission project, which varies on a case-by-case basis; as a result, there is unlikely to be a universal solution [11]. Nonetheless, industry can follow best practices to identify all potential benefits and allocate them in approximate proportion to beneficiaries, such as those analyzed by the Brattle group [12]. With RTOs implementing a more comprehensive cost allocation model to support new transmission infrastructure, grid modernization can proceed at an accelerated pace.

\section{Joint Evaluation Processes for Interregional}

Transmission: Recognizing that the benefits of an individual transmission line can affect the network far beyond the local environment, FERC Order No. 1000 states that an interregional process for transmission development between RTOs must exist [13]. For example, a region that imports renewable electricity from another region benefits from low-cost, green energy, while the exporting region also benefits from energy sale revenues. However, Order No. 1000 indicates that each RTO must approve any regional transmission through its own cost allocation processes, and does not specify how a joint evaluation between several RTOs should be carried out [14].

As a result, a project that presents net benefits across two RTOs may not be ultimately approved, because one eliminates the project first through its own regional planning process [15]. Specifically, separate regions may consider different benefits when evaluating a given project, or attempt to minimize costs for their constituents without considering the cumulative benefits across all recognized categories, and in all affected RTOs. This means that a "least common denominator" approach is taken, which can lead to fewer approvals and inequitable cost allocation [16]. Additionally, the present lack of coordination among RTOs, with regards to planning assumptions and metrics, contributes to different evaluation outcomes. Revising FERC Order No. 1000 to require an interregional evaluation framework, using commonly agreed-upon assumptions and all benefits acknowledged by each RTO, would improve transparency and fairness in evaluating projects across regions.

Permitting: Siting and permitting new proposed transmission lines is another obstacle to development. Several regulatory approvals at the state level may be required for transmission lines or upgrades, giving each state effective veto power in a regional transmission project. The Energy Policy Act of 2005 authorizes FERC to regulate the siting of transmission infrastructure to underserviced areas, and to intervene in multi-state transmission projects under certain conditions; however, this backstop authority has rarely been used [17] "Pass-through" communities within these states may feel that they unfairly shoulder the burdens of the proposed transmission [18]. Common concerns include disruption to local environments and unsightly infrastructure. These reactions can cultivate coordinated "Not In My Backyard" sentiments that jeopardize the permitting of transmission projects. Further, state residents may oppose out-of-state energy sources on the grounds that local generation would provide more employment for their immediate communities [19].

Several process considerations can serve to address stakeholder concerns regarding transmission planning and ensure projects meet minimal delays. The first would be early coordination and solicitations for feedback between project developers, the local utility or RTO, state authorities, and affected citizens to improve the speed and likelihood of transmission approval. For instance, the Great Northern Transmission Line (GNTL) completed the final environmental impact study in 18 months, as compared to the Northern Pass Transmission (NPT) line which took seven years to complete its impact study. This may be in part explained by the fact GNTL held over 70 stakeholder workshops and addressed comments during the pre-application filing process, while the NPT had no public involvement [18]. In some cases, consent from intervening states and affected communities may be procured by promising them a percentage of new revenue generated from the increased transmission capacity. Some communities may also be receptive to subsidized electricity obtained by tying in to the new transmission lines.

Second, the regulatory approval process might be avoided in some cases by utilizing the land that already contains existing transmission. Numerous strategies could be used to increase transmission capacity while bypassing some of the regulatory hurdles that would lead to project delays and contingencies. Reed et al. review several technical options to upgrade or repurpose existing transmission lines to increase their capacity without the environmental and social disturbances of running new lines [20]. In some circumstances, new lines can be installed along existing transmission corridors (i.e., where lines and poles are physically located), which can reduce the costs and delays 
associated with constructing transmission infrastructure where none existed previously. State planners and RTOs should demonstrate that existing rights-of-way and infrastructure are already at capacity before proposing to expand transmission capacity with additional lines [20].

Recognizing Benefits of Non-Transmission Alternatives: Increasingly, Non-Transmission Alternatives (NTAs) are recognized for their potential role in improving grid capacity and reliability without requiring new traditional transmission and distribution infrastructure. NTAs encompass a range of programs and technologies including substation upgrades, efficiency improvements, distributed renewable energy, and energy storage. Smart grid technologies like smart meters encourage less energy use, especially during periods when demand tends to peak. These numerous types of NTAs can considerably reduce grid maintenance costs. Despite their growing relevance, NTAs have received limited consideration due largely to two key barriers to wider NTA implementation: economic incentive and lack of regulatory clarity.

The current formula governing the process by which utilities set the prices charged to consumers requires the majority of utility return to be earned on capital investment (i.e., traditional poles-and-wires infrastructure). NTAs are most often classed as operating expenses, which can only be passed through to the consumer at-cost, for no return. This makes NTAs less attractive to utilities, even when they might fulfill requirements at lower cost. Some utilities such as Central Maine Power have called for a new incentive structure that treats NTA investments in a similar way as transmission and distribution [21].

Federal directives on NTA consideration are central to ensuring appropriate consideration going forward. As it stands, FERC Order No. 1000 requires that regional planning entities consider NTAs, but does not specify the method of analysis or require that regional planning entities develop processes. Without direct guidance to spur NTA analysis, traditional transmission projects remain the default solution. The burden of proposing innovative NTA solutions then falls on external stakeholders, such as public interest groups, who may lack the necessary technical expertise to compete with transmission proposals, or NTA providers, who have a financial interest in the outcome [22].

Welton recommends that FERC update Order No. 1000 to require RTO-directed processes to assess regional NTA opportunities [23]. They suggest that RTOs are best suited, in terms of both expertise and financial resources, to assess NTA feasibility. A FERC requirement would force transmission planners to develop appropriate metrics for evaluating traditional and innovative grid solutions. Requiring regional analysis would allow FERC to compile best practices, without prescribing top-down metrics. However, such a requirement may not impact NTA deployment if FERC does not first require appropriate cost allocation [23].

Alternatively, FERC could leave Order No. 1000 unchanged, and rely on existing regional momentum. Several states have taken ambitious steps toward considering NTAs. In 2018, the California Public Utilities Commission (CPUC) issued a ruling to expand opportunities for third-party distributed energy resources (DERs), such as rooftop solar panels, to substitute for investments in transmission and distribution infrastructure. Further, CPUC ordered utilities to consider third-party DERs in their recurring grid needs assessments [21]. At least eleven states have advanced proposals aimed at incorporating DERs and other NTAs in distribution planning [21]. These state and regional actors may better understand their geographic and demographic requirements than federal regulators, while a federal requirement might limit innovative deployment.

While traditional state-level utility planning processes still might lead to NTA development without changes to Order No. 1000, suitable compensation for co-benefits provided to the grid is not ensured. These benefits can include mitigating congestion, reducing air pollutants and water usage, and cutting overall land use. While the work in many states to incorporate NTAs in planning is promising, revising FERC Order No. 1000 could promote more numerous and widespread avenues for mitigating carbon and maintaining grid reliability-all while reducing costs.

\section{Conclusions}

A major overhaul of the U.S. transmission system is needed, both to maintain the reliability of aging infrastructure, and also to keep pace with modern decarbonization initiatives. Renewables, distributed energy generation, electric vehicles, and energy storage are shifting the patterns of electricity use away from the model on which the U.S. grid was built decades ago. Transmission expansion and upgrades will be critical to the future success of the U.S. grid. Collaborative approaches to cost allocation, project evaluation, and siting can alleviate some difficulties in planning infrastructure projects that offer widespread, long-term, and hard-to-quantify benefits. Additionally, non-transmission alternatives (NTAs) are a promising option to facilitate optimal use of existing infrastructure, leading to reduced system costs. While some regions are already embracing NTAs, modest policy revisions could enable NTAs to compete against traditional infrastructure projects as viable options. Modern policies as well as technologies will support the transmission system's vital role in the Energy Transition.

\section{Acknowledgements}

The views expressed herein are the views and opinions of the authors and do not reflect or represent the views of Charles River Associates or any of the organizations with which the author is affiliated.

\section{Citation}

Kasam-Griffith et al. Transmission Transition: modernizing U.S. transmission planning to support decarbonization. MIT Science Policy Review 1, 87-91 (2020). 


\section{Open Access}

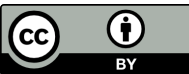

This MIT Science Policy Review article is licensed under a Creative Commons Attribution 4.0 International License, which permits use, sharing, adaptation, distribution and reproduction in any medium or format, as long as you give appropriate credit to the original author(s) and the source, provide a link to the Creative Commons license, and indicate if changes were made. The images or other third party material in this article are included in the article's Creative Commons license, unless indicated otherwise in a credit line to the material. If material is not included in the article's Creative Commons license and your intended use is not permitted by statutory regulation or exceeds the permitted use, you will need to obtain permission directly from the copyright holder. To view a copy of this license, visit http://creativecommons.org/licenses/ by $/ 4.0 /$.

\section{References}

[1] 2017 infrastructure report card. Tech. Rep., American Society of Civil Engineers (2017). Accessed: September 2020.

[2] Electricity generation and delivery: Grid. Tech. Rep., ARPA-E (2019). Accessed: September 2020.

[3] About $60 \%$ of the U.S. electric power supply is managed by RTOs. Online: https://www.cdc.gov/antibioticuse/stewardship-report/index.htmI (2011). Accessed: September 2020.

[4] Fed. Energy Regulatory Comm'n v. Elec. Power Supply Ass'n, 577 U. S. Online: https://supreme.justia.com/cases/ federal/us/577/14-840/ (2016). Accessed: September 2020.

[5] Kormos, M. \& Ott, A. Operational events and market impacts january 2014 cold weather. Online: https://pjm.com//media/library/reports-notices/weatherrelated/20140509-presentation-of-january-2014cold-weather-events.ashx?la=en (2014). Accessed: September 2020.

[6] Online: https://upload.wikimedia.org/wikipedia/ commons/1/Id/RTO_v1.jpg Accessed: September 2020.

[7] Order No. 1000, Regional Transmission Organizations, 18 CRF $\S 35.34$ (2006).

[8] Informing the transmission discussion. Tech. Rep., ScottMadden, Inc. (2020). Accessed: September 2020.

[9] ERCOT. LCRA, AEP announce agreement to improve transmission system. Online: http://www.ercot.com/ news/releases/show/71 (2001). Accessed: September 2020.

[10] Illinois Commerce Commission v. FERC. Online: https:// caselaw. findlaw.com/us-7th-circuit/1633852.html 721 F.3d 764 (2013). Accessed: September 2020.

[11] Implementing EPA's clean power plan: A menu of options. Tech. Rep., National Association of Clear Air Agencies (2015). Accessed: September 2020.

[12] Chang, J. W., Pfeifenberger, J. P. \& Hagerty, J. M. The benefits of electric transmission: Identifying and analyzing the value of investments. Online: https://cleanenergygrid. org/uploads/WIRES:20Bratt le20Rpt:20Benefits\% 20Transmission:20July202013.pdf (2013). Accessed: September 2020.

[13] Grid vision: The electric highway to the 21st century economy. Tech. Rep., American Wind Energy Association (2019). Accessed: September 2020.

[14] Eto, J. H. Planning electric transmission lines: A review of recent regional transmission plans. Online: https://www.energy.gov/sites/prod/files/2017/
$01 / f 34 / P 1$ anning20Electric20Transmission응 20 Lines $-A \circ 20$ Review200f20Recent20Regional응 20Transmissiono20Plans.pdf (2016). Accessed: September 2020

[15] OMS. Interregional transmission coordination issues: FERC docket no. AD16-18. Online: https://www.misostates. org/images/stories/Seams_Coordination_Efforts/ November_17_2019/Business_Item_1_Summary_of_ FERC_Technical_Conferences_with_Seams_Planning_ Topics.pdf (2019). Accessed: September 2020.

[16] DOE. Summary of discussion of DOE workshop on electric transmission development and siting issues. Online: https://www. energy.gov/sites/prod/files/2019/ $01 / f 59 / D O E \div 20 N o v e m b e r \% 202018 \% 20$ Transmission\% 20 Is sues:20Workshop2 $20 \% 20$ Meeting 20 Summary응 20 January2019.pdf (2019). Accessed: September 2020.

[17] Energy Policy Act of 2005, 42 U. S. C. ch. $149 \$ 15801$ et seq. (2005).

[18] Spector, J. The controversy surrounding massachusetts $\$ 1.6 \mathrm{~b}$ hydropower transmission line. Online: https: //www. energy.gov/sites/prod/files/2019/01/ f59/DOE20November\%20201820Transmission\% 20 Is sues:20Workshop는 $20 \% 20$ Meeting 20 Summary응 20 January2019.pdf (2018). Accessed: September 2020.

[19] DOE. Notice of proposed rulemaking on the integrated interagency pre-application process (IIP) on electric grid transmission. Online: https://www.energy.gov/ oe/downloads/notice-proposed-rulemakingintegrated-interagency-pre-applicationprocess-iip-electric (2016). Accessed: September 2020.

[20] Reed, L., Dworkin, M., Vaishnav, P. \& Morgan, M. G. Expanding transmission capacity: Examples of regulatory paths for five alternative strategies. Electr. J. 33, 106700 (2020). https: //doi.org/10.1016/j.tej.2020.106770.

[21] Girouard, C. Top 10 utility regulation trend of 2019 - so far. Online: https://blog.aee.net/top-10-utilityregulation-trends-of-2019-so-far (2019). Accessed: September 2020 .

[22] Hempling, S. Non-transmission alternatives': FERC's 'comparable consideration' needs correction. Online: https: //www. scotthemplinglaw.com/files/pdf/ ppr_nta_comparable_consideration_0513.pdf (2013). Accessed: September 2020.

[23] Welton, S. Non-transmission alternatives. Harv. Environ. Law Rev. 39, 457-513 (2015). 